\title{
Tapada das Necessidades em Lisboa A história de um jardim esquecido
}

\author{
João Albuquerque Carreiras *
}

\begin{abstract}
RESUMEN: SUMMARY:
O trabalho apresentado consiste numa análise histórica da Tapada das Necessidades, jardim situado na cidade de Lisboa, formando um dos seus maiores espaços verdes.

A Tapada foi construida por D.João $V$, o monarca que em Portugal mais simbolizou o Absolutismo, reflectindo-o nas suas criações Barrocas.

Com o Liberalismo surge $D$. Fernando, que vai ser o intérprete de uma enorme transformação da tapada, protagonizando o período mais importante na sua evolução.

A história da Tapada entranha-se na própria história de Portugal, acompanhando o absolutismo, a

transição para o liberalismo, os últimos movimentos da monarquia e os primeiros passos da República.

The presented work consists in a historical analysis of the Tapada das Necessidades, a garden situated in the city of Lisbon, forming one of its bigger green spaces.

The Tapada was built by D.João $\mathrm{V}$, the monarch that in Portugal more symbolized the Absolutism, reflecting it in its Baroque creations.

With the Liberalism appears D.Fernando, who will be the interpreter of an enourmous hashing of the Tapada, carrying out the more important period of its evolution.

The history of the Tapada penetrates in Portugal own history, following the absolutism, the transition for the liberalism, the last moves of the monarchy and the first steps of the republic.
\end{abstract}

Os jardins são espaços únicos nos quais a evolução e a marca do tempo se tornam fundamentais para a sua compreensão. Tratando-se de jardins privados, a história que contam é a da família dos seus proprietários, com seus altos e baixos, as fases mais ricas e as de maior contenção.

Nos jardins reais é a história do poder e dos próprios países que se reflecte nos jardins, na sua estrutura, na sua filosofia, nas suas peculiaridades. A Tapada das Necessidades é um bom exemplo disso. Jardim real 
desde a sua construção até ao fim da monarquia, teve os seus altos e baixos, todos eles acompanhando a história de Portugal. Por isso se torna curiosa a sua história e evolução, porque com ela se pode acompanhar a história de Portugal nos últimos 250 anos. Na tapada podemos ver as marcas do absolutismo, as mudanças do liberalismo, o declínio da monarquia, o caos da $1^{a}$ República. Todos estes marcos estão indelevelmente ligados a este espaço, quer como palco destes acontecimentos, quer como expressão dos mesmos.

\section{A Lenda}

A história das Necessidades começa, como muitas outras, com uma lenda. A origem desta lenda data de 1580 , altura em que Lisboa foi assolada por uma devastadora peste que durou mais de 20 anos. A peste teve como consequência que grande número de pessoas escapassem para o campo, em busca de melhores ares que lhes permitissem resistir a este mal.

Foi na Ericeira, vila próxima de Lisboa, que um casal em fuga da peste rezava amiúde numa ermida onde se encontrava uma imagem de Nossa Senhora da Saúde. Como conseguiram escapar à peste, atribuíram esta graça ás preces feitas a Nossa Senhora. Quando regressaram a Lisboa fizeram questão de trazer consigo a imagem, procurando abrigá-la de forma digna, para tal construindo uma ermida no Alto de Alcântara (1606)

Com o tempo as graças concedidas por esta imagem foram sendo divulgadas, levando ao aparecimento de grande número de devotos que a ela recorriam, devido ás suas aflições e necessidades. Surge assim a designação de Nossa Senhora das Necessidades1.

A ligação da família real a Nossa Senhora das Necessidades começa quando D. Pedro de Castilho, conselheiro de D.João IV, compra as casas anexas à Ermida para aí construir a sua residência. Nessa época, vivia D. João IV no Paço de Alcântara, sendo habituais as suas visitas a este local, o que o levou a tornar-se seu protector. D. Afonso VI e D. Pedro II herdam do pai esta devoção?.

Quando em 1705 D. Pedro II está gravemente doente reclama a presença da imagem, e a sua devoção é recompensada através das rápidas

1 Ferrāo, Leonor, A Real Obra de Nossa Senhora das Necessidades, Lisboa, Ed. Quetzal, 1994, pág. 21

2 Cóte-Real, Manuel Henrioue, Palácio das Necessidades, Lisboa, Ministério dos Negócios Estrangeiros, 1983, pág. 12 
melhoras que o levaram a escapar da morte eminente. A devoção à virgem de D. Pedro II transmite-se ao seu filho, D.João V, sendo habituais as suas idas à ermida. Tal devoção levou a que ao ser acometido por uma paralisia, em 10 de Maio de 1742, pedisse que lhe fosse trazida a imagem de Nossa Senhora das Necessidades para o quarto onde irá ficar durante os oito anos que durou esta doença, sendo-lhe atribuida a resistência oferecida à mesma.

Como agradecimento pelas graças concedidas, D.João $V$ imaginou um projecto capaz de engrandecer Nossa Senhora das Necessidades. "Ora já sabemos que $D$. João $V$ não era rei que pagasse mal os serviços de que se aproveitava; $e$, muito principalmente os serviços espirituaes tinham para ele um preço elevadíssimo. Querendo, pois patentear à santa imagem toda a sua gratidão pela companhia que Ihe estava fazendo, D. João $V$ converteu a breve trecho em magnífica igreja a antiga e despretensiosa ermida, e junto a esse pomposo templo mandar construir um palácio para residir. Não contente com isso, lembrou-se o achacado soberano de fundar aí um convento, que entregou depois aos padres da Congregação do Oratório4." Surgia então a obra das Necessidades.

\section{João V - Absolutismo - Barroco - Construção}

A obra das Necessidades nasce, pois, com D. João V. Ele é o seu mentor e executor. A sua influência no projecto é decisiva: marca o programa a cumprir, estabelece as regras, impõe conceitos. As suas obras foram sempre reflexo da sua pessoa.

$D$. João $V$ foi um rei absoluto e barroco, numa época em que esta forma política estava em decadência por toda a Europa. Foi o Rei-Sol à escala portuguesa: menos absoluto, menos radioso, menos grandioso. Tal facto reflecte-se na produção artística durante o seu reinado -particularmente na arquitectura- pois tal como com outros soberanos absolutos, as suas ideias e intenções sobrepõem-se ao processo de criação artística.

$A$ vida de $D$. João $V$ está marcada por grandes obras, que em muito contribuíram, pela sua dimensão, para o cognome de $O$ Magnífico. O Palácio de Mafra surge-nos como o seu grande projecto, a obra de uma vida, para onde foram canalizadas todas as atenções, energias e capitais. Uma Versailles à portuguesa, a uma escala menor, mas com uma 
ideia conceptual semelhante. A imposição de uma ideia e de uma vontade de afirmação que ultrapassa os critérios arquitectónicos e em ultima instância a própria natureza. A arquitectura surge, a exemplo de Versailles, como uma forma de afirmação de poder.

Há, no entanto, um ponto que diferencia a sua atitude e a de Luís XIV; para $D$. João $V$ o papel da Igreja é preponderante na sua atitude perante a vida. Esta atitude reflecte-se na envolvência religiosa das suas grandes obras: Mafra foi uma oferta a Deus para que este lhe proporcionasse herdeiros, as Necessidades um agradecimento das graças concedidas para a cura de uma doença. A obra das Necessidades surge como o seu derradeiro testemunho e a sua última prova de Fé.

\section{1 - Palácio / Igreja / Convento/Obelisco}

A Obra das Necessidades constitui um conjunto que, como tal, não pode ser analisado por partes. Ao jeito dos palácios barrocos, a Igreja, o Convento, a Cerca, o Palácio e a Praça do Obelisco constituem um todo, uma obra que foi pensada e projectada como uma unidade. (Fig. 1)

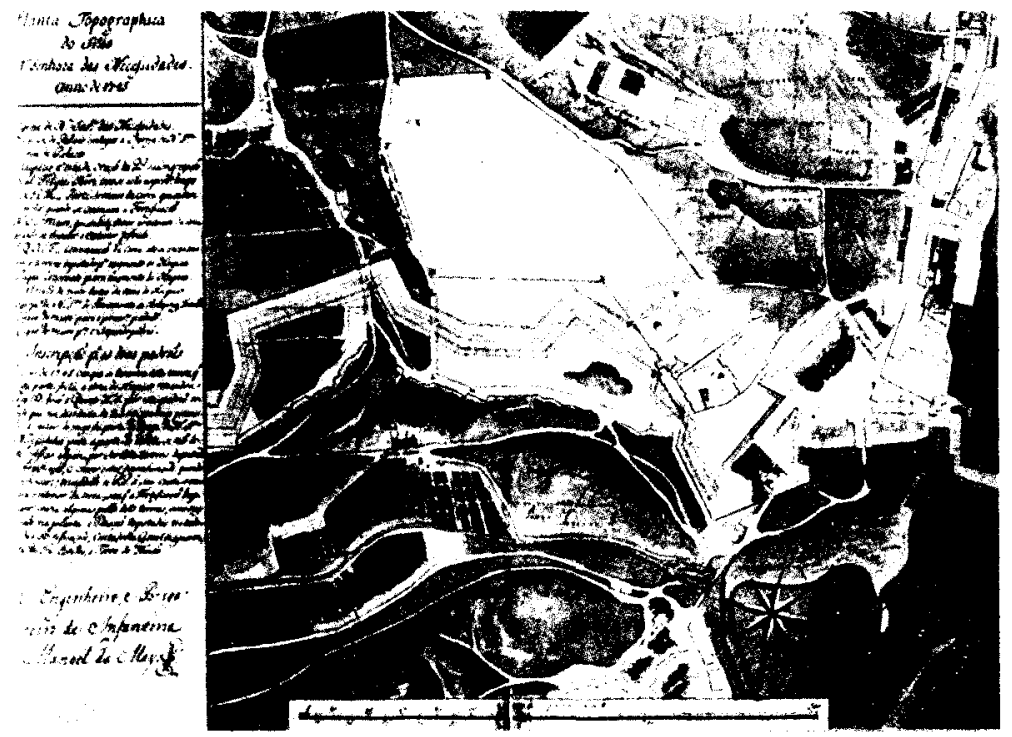

Fig.1 - Planta da Tapada das Necessidades, antes da construção da Cerca - 1745

In: Arquivo Nacional da Torre do Tombo (ANTT) 
O núcleo desta obra encontra-se na Igreja; a partir dela se organizam os restantes edifícios, nomeadamente o Palácio e o Convento. Foi erguida sobre o local da antiga Ermida, construída para albergar a imagem de Nossa Senhora das Necessidades. Constitui a representação terrena da entidade a celebrar nesta obra. Quando D.João $V$ decidiu agradecer a Nossa Senhora os favores por ela prestados, por certo que a sua primeira intenção foi a de lhe prover um abrigo à sua altura.

Em redor da Igreja ergue-se o microcosmos imaginado por D.João $\mathrm{V}$, uma cidade ideal, pensada e construída como pequena réplica das cidades do Absolutismo5. Num mesmo espaço temos a casa do rei celeste -a Igreja, a casa do rei terreno- o Palácio, a casa da família religiosa o Convento, o polo de atracção para o espectáculo do poder -a Praça6, os campos de recreio- a Cerca.

A fachada do palácio desenvolve-se em redor da capela -estendendo a sua volumetria na horizontal- sendo constituída por cinco linhas articuladas que the dão um enorme dinamismo e movimento. O palácio domina o rio, aproveitando a praça fronteira à fachada, sendo que a exposição a sul the garante grande luminosidade. (Fig. 2)

Em frente à Igreja e ao palácio, como que numa varanda para o mundo, surge a praça do Obelisco. Virada ao rio numa impressionante posição de dominio, tem por elemento focalizador um obelisco que celebra o aniversário de $\mathrm{D}$.João $\mathrm{V}^{7}$. Em conjunto com a fonte e a praça que o envolve ${ }^{8}$-que remetem claramente para o barroco italiano- afirma a força e poder do Rei.

João Albuquerque Carreiras

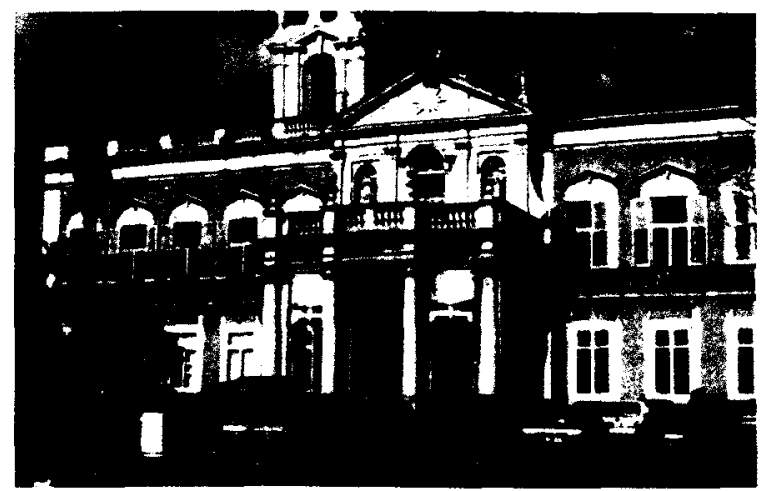

5 FERRĀo, LeONOR, op. cit., pág. 248, nota 44

6 FERRĀo, LEONOR, op. cit., pág. 248, nota 44

7 O sexagésimo sexto aniversário, a 22 de Outubro de 1747

8 A sua autoria não é conhecida, tendo sido atribuido a nomes como: João Frederico Ludovice, Alessandro Giusti e Carios Mardel 
A autoria do projecto para a obra das Necessidades não pode ser identificada com exactidão, vários autores escreveram sobre o assunto, mas nenhuma hipótese é conclusiva.

Ao mandar edificar o palácio, o Rei pensou por certo que ele, ou a Rainha, o iriam habitar. No entanto, apesar de todo o empenho posto por D. João $V$ na construção desta obra, a sua morte precoce, em 31 de Julho de 1750 , impediu-o de assistir à sua conclusão.

\section{2 - A Cerca/Tapada}

D. João V, ao concretizar o seu projecto para as Necessidades, teve como objectivo importante a construção de uma cerca digna para os padres do Convento. Para concretizar esta obra foi chamado o Ajudante Eng. Custódio de Sá e Faria, para "desenhar todas as plantas necessárias para a cerca, e jardins»9. (Fig. 3)

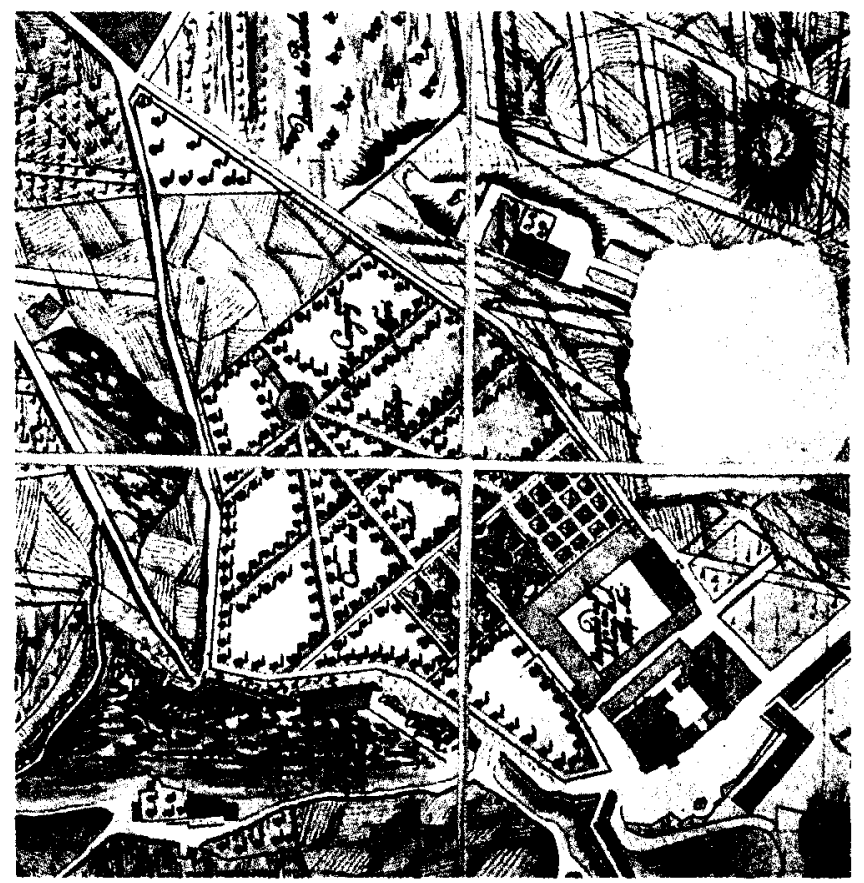

Fig.3 - Planta da Tapada das Necessidades em 1756. In: Museu da Cidade de Lisboa

9 Viterbo, F. Sousa, Dicionário Histórico e Documental dos Arquitectos e construtores portugueses ou ao serviço de Portugal, Tomo III, Lisboa, Imprensa Nacional Casa da Moeda, 1922, págs. 1-2 
Quando foi construída, a Cerca seria «um jardim decorado de estátuas e vasos de mármore, com seu lago no meio: de compridas ruas de bosque, perfeitamente alinhadas, cruzandose, e encontrando-se em diversos largos não muito espaçosos, onde formavam uma estrella, da qual cada rua era um raio; de pomares de laranja, e outras frutas nos espaços que as ruas deixavam livres, mas encaixilhados em arvoredo silvestre; de uma horta ajardinada; de uma casa de regalo no fundo do bosque, com sua pequena cascata dentro, e fóra um grande lago circular, tudo assombrado de frondosas árvores, e finalmente de várias obras de ornato10".

Este texto de Vilhena Barbosa permite confirmar os dados cartográficos para a composição da cerca dos padres Oratorianos (Fig. 14a). A norte do Convento situava-se o Jardim de Buxo, e ao seu lado, a uma cota superior, a Horta dos Frades. Acima destes parterres desenvolvia-se um terreno

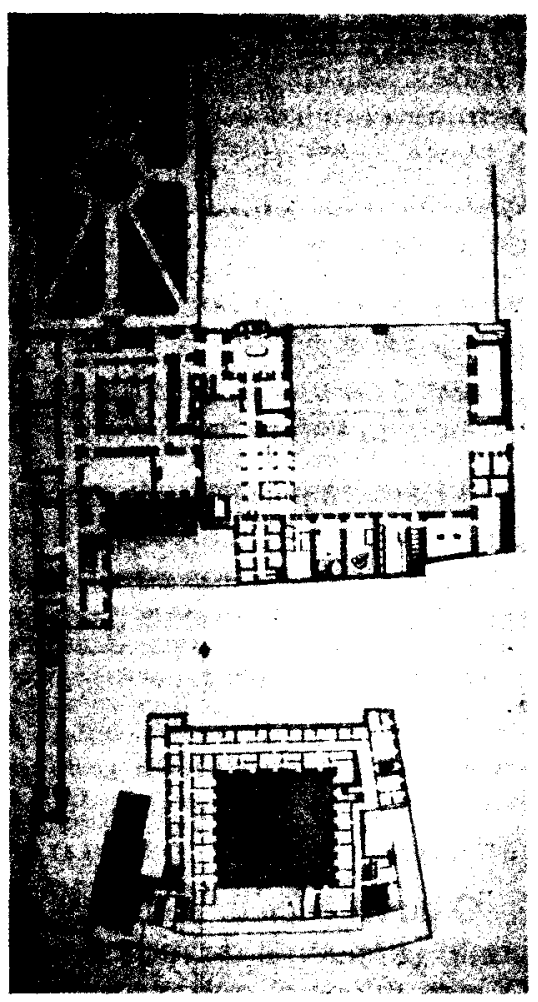

Fig.4 - Planta do Palácio e Jardim de Buxo In: ANTT cercado, com um traçado típico dos jardins barrocos, com grandes eixos convergindo num lago circular central. Um dos eixos era formado por uma cascata com origem num grotto. Os talhões formados por estes eixos, ao contrário dos parterres ornamentais de buxo talhado, estariam ocupados sobretudo por pomares (especialmente de citrinos), demonstrando a função de cerca conventual de produção para a congregação. A planta de 1844 (Fig. 7), que na zona norte da tapada deve conter uma estrutura aproximada à original, nomeia cada talhão, sendo que em alguns se pode estabelecer a sua ocupação. Além dos pomares, é de citar a presença de vinha e de uma larga área de terra de semeadura, situada no extremo norte, junto ao moinho, confirmando a vocação de produção agrícola.

10 Barbosa, INácio de VILHena, "Real Quinta das Necessidades", Arquivo Pitoresco, n. ${ }^{2}$ 18, Lisboa 1862, pág. 142 
O Jardim de Buxo encontra-se a norte do convento, junto à Horta dos Frades. Tem um formato rectangular, rematado por muros, e dispõe a sua estrutura em torno de um lago central (Fig. 4). Estando a uma cota inferior à Horta dos Frades, esta é superada por um muro de suporte. Na face oposta ao convento encontra-se um muro que teria estátuas representando as virtudes.

A estrutura do jardim era regular, num estilo quase renascentista, com um desenho muito elaborado, formando como que um rendilhado, um parterre de broderie formado pela sebe em buxo, que delimitava os caminhos de saibro, e por um lago central.

A Este do jardim de buxo, mas a uma cota superior, localiza-se a antiga Horta dos Frades. Aqui deparamo-nos com uma re-interpretação do hortus conclusus dos conventos medievais, ou seja, uma horta ornamentada ligada à produção de plantas necessárias ás boticas conventuais.

A estrutura que observamos na planta original é muito simples, longe do ornamento do jardim de buxo (Fig. 5). A sua localização fronteira ao jardim de buxo é curiosa, pois estabelece um contraponto entre um jardim conventual, com uma função produtiva, e um jardim mais palaciano, que tem como objectivo apenas o ornamento para recreio.

O ponto nuclear da Cerca era sem dúvida o Lago Circular. Era este o ponto confluente da rede de caminhos que definia a estrutura da Cerca. O eixo principal que o atravessava era formado por um dos lados pela cascata outrora existente, que tinha origem num grotto.

No topo do grotto existiu um estranho edifício: o observatório astronómico dos padres oratorianos 11 , onde o Padre João Chevalier efectuava os seus estudos 12 .

O moinho foi a primeira testemunha da obra das Necessidades e, também, do carácter agrícola da zona onde está implantado. A zona mais alta da Tapada foi por muito tempo terra de cereais (vulgo de semeadura), confirmando a função de produção normalmente associada ás cercas conventuais.

No topo norte da tapada, acima das terras de semeadura, localizavase o campo de Jogo da Bola, construido no decorrer do século XVIII. Este

11 Ribeiro, Jose Silvestre, Historia dos estabilicimentos scientificos litterarios e artisticos de Portugal nos successsivos reinados da monarchia, Lisboa, Academia Real das Sciências, 1871-1914, Tomo III - 1873, pág. 348

12 Carvalho, José Maria de, Catálogo Oficial da V Exposição Nacional de Floricultura, Lisboa, C.M.L., 1944, págs. $8-9$ 


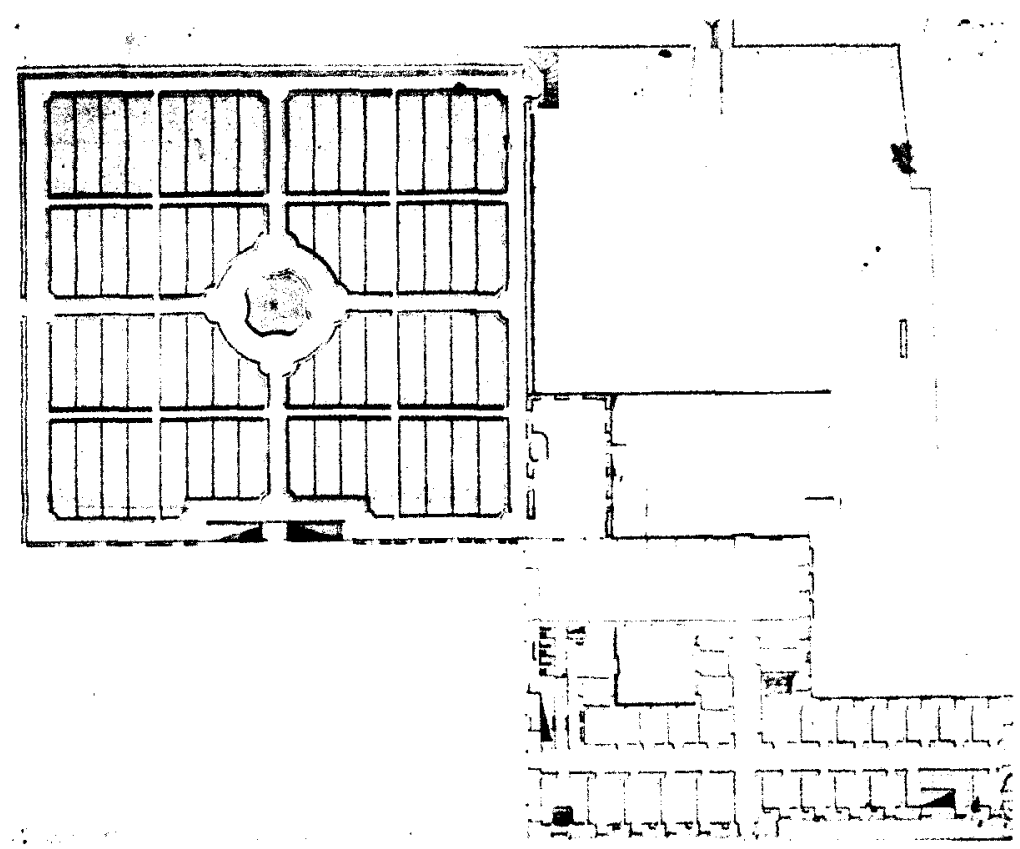

Fig.5 - Planta do Palácio e Horta dos Frades. In: ANTT

jogo era muito popular na época -confirmando a função lúdica dos jardins- pelo que aparecia em muitas cercas conventuais.

$A$ D.João $V$ sucede o seu filho $D$. José que opta por não habitar o palácio, levando a que os primeiros habitantes das Necessidades tenham sido dois irmãos de D. João V: o infante D. António e o infante D. Manuel, ambos falecidos no palácio (em 1757 e 1766, respectivamente).

Após a morte destes príncipes, passaram anos sem que o Palácio das Necessidades fosse habitado pela família Real, tomando a única função de acolher hóspedes reais.

Só em 1828, altura em que D. Miguel escolheu as Necessidades, a família real voltou a residir por temporadas no palácio. Após a conquista de Lisboa, em 24 de Julho de 1833, também D. Pedro IV permaneceu nas Necessidades.

Dois importantes factos históricos, ocorridos no Palácio das Necessidades, the deram funções diferentes. $O$ estabelecimento no palácio da Academia das Ciências, entre 1780 e 1791, e a realização da primeira 
sessão das cortes extraordinárias, em 1821, facto ainda hoje lembrado na toponímia do Pátio das Cortes 13 .

\section{Fernando II - Liberalismo - Romantismo - Restruturação}

O primeiro monarca a estabelecer-se definitivamente no Palácio das Necessidades foi a Rainha D. Maria II. Esta soberana escolheu, em 1833, o palácio como residência oficial aquando o seu casamento com o príncipe Augusto de Leuchtenberg. A morte precoce deste príncipe, em 28 de Março de 1835, leva a que este casamento seja de curta duração.

O segundo casamento de D.Maria -com D.Fernando de Saxe Coburgo Gotha, mais tarde II de Portugal- teve lugar, por procuração, no dia 1 de Janeiro de 1836.

Para D.Fernando este casamento revestia-se de vários contornos difíceis, uma vez que a sua educação não fora dirigida para papéis políticos e militares importantes e Portugal era um país culturalmente distinto da sua terra natal, e com o qual, antes do casamento, não tinha qualquer ligação.

O cognome de D.Fernando -o Rei-Artista- revela bem a sua personalidade e forma de estar na vida. Por educação e vivência sempre esteve intimamente ligado ao mundo artístico.

O príncipe, tendo nascido em Viena de Áustria, era sobrinho do duque reinante de Saxe Coburgo Gotha, Ernesto I. O ducado situava-se na Turíngia, estando rodeado de uma grande área florestal. Cedo D.Fernando se encontrou ligado intimamente com a natureza, principalmente nas suas estadias nas várias casas de campo da família, das quais podemos destacar Rosenau, Kallenberg e Reinhardsbrunn. D.Maria secundava o marido nesta paixão, facto que reflectiu na educação de seus filhos, cedo Ihes incutindo o gosto pela natureza.

A vida no palácio estava indubitavelmente ligada aos jardins, passando a família muito do seu tempo por eles passeando. Os príncipes criavam aves e cultivavam os seus próprios canteiros, supervisionados por Bonnard, director do Real Jardim das Necessidades, como se pode comprovar neste trecho de uma carta da Infanta D.Maria Ana a seu pai; "Mon jardin devient de jour en jour plus joli. Bonnard m'a planté des verbenes, un pied blanc, un bleu, et l'autre rouge ${ }^{14}$ ".

13 Referindo-se a um Pátio no interior do palácio

14 Carta da Infanta D. Maria Ana a seu pai D. Fernando, A.H.M.F. (Arquivo Histórico do Ministério das Finanças), Cartório da Casa Real, Maço 10, doc. 180-3, Abril de 1852 


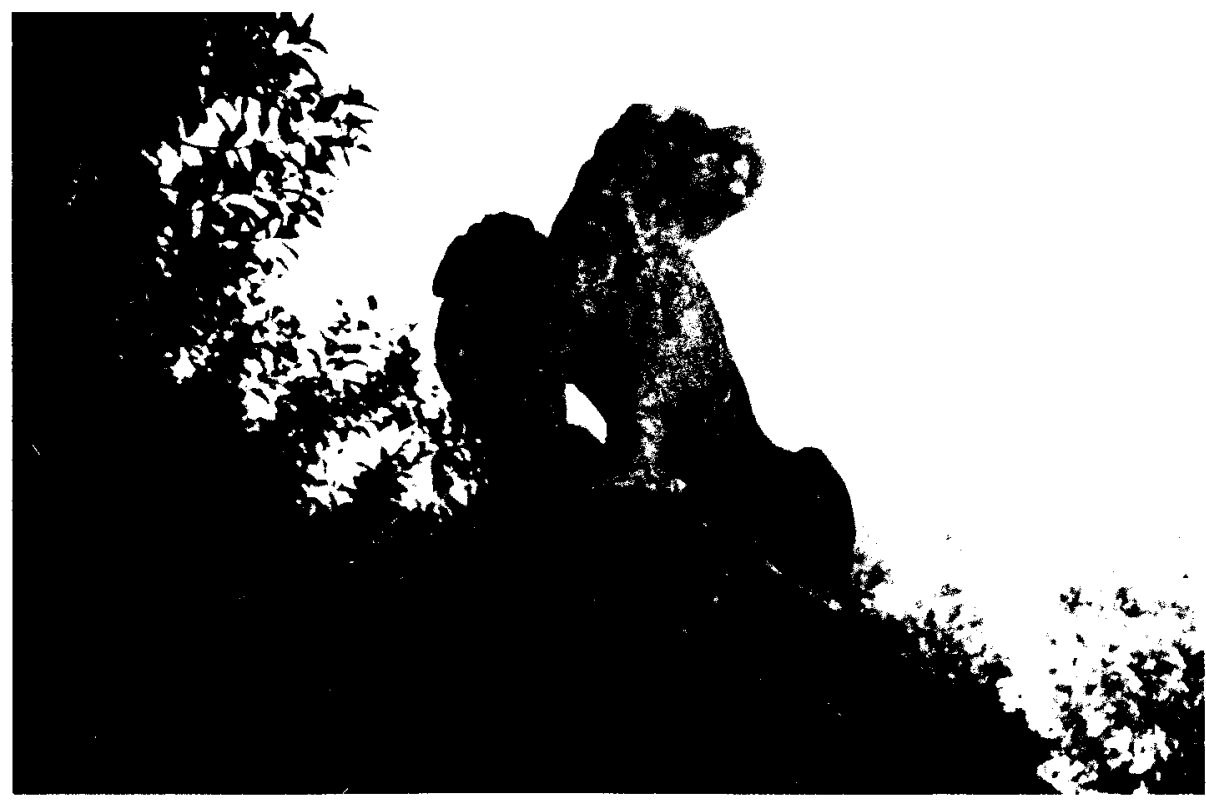

Fig.6 - Fonte com um Leão. Foto: João Albuquerque Carreiras

A natureza e as ciências naturais ocupavam grande espaço nos interesses de D.Fernando. Era proprietário de uma excelente biblioteca de onde se destacavam os temas da Botânica e da História Natural. Um dos projectos que alimentou para as Necessidades foi a criação de um museu de História Natural, facto por certo influenciado pela existência de um em Coburgo. Para tal, os seus filhos D. Pedro e D. Luiz empreenderam uma viagem pela Europa, na qual além dos passeios por jardins botânicos, museus e palácios, tiveram por objectivo visitar colecções zoológicas e adquirir espécimens para este museu.

Ao chegar às Necessidades, D.Fernando por certo terá experimentado uma certa sensação de desconforto. Os jardins do palácio eram de uma estrutura barroca, rígida, formal (Fig. 14a), em tudo diferente dos belos parque à inglesa que pontuavam na sua terra natal. A restruturação dos jardins foi certamente encarada como uma das suas prioridades. Para a execução deste projecto D.Fernando contou com os préstimos do jardineiro francês Bonnard.

Bonnard foi nomeado por D.Fernando para o cargo de director dos Jardins Reais, ficando como tal com a responsabilidade do Jardim das Necessidades. A sua competência levou o rei a convidá-lo para dirigir a Escola de Horticultura que resolveu fundar, com sede nas Necessidades. 


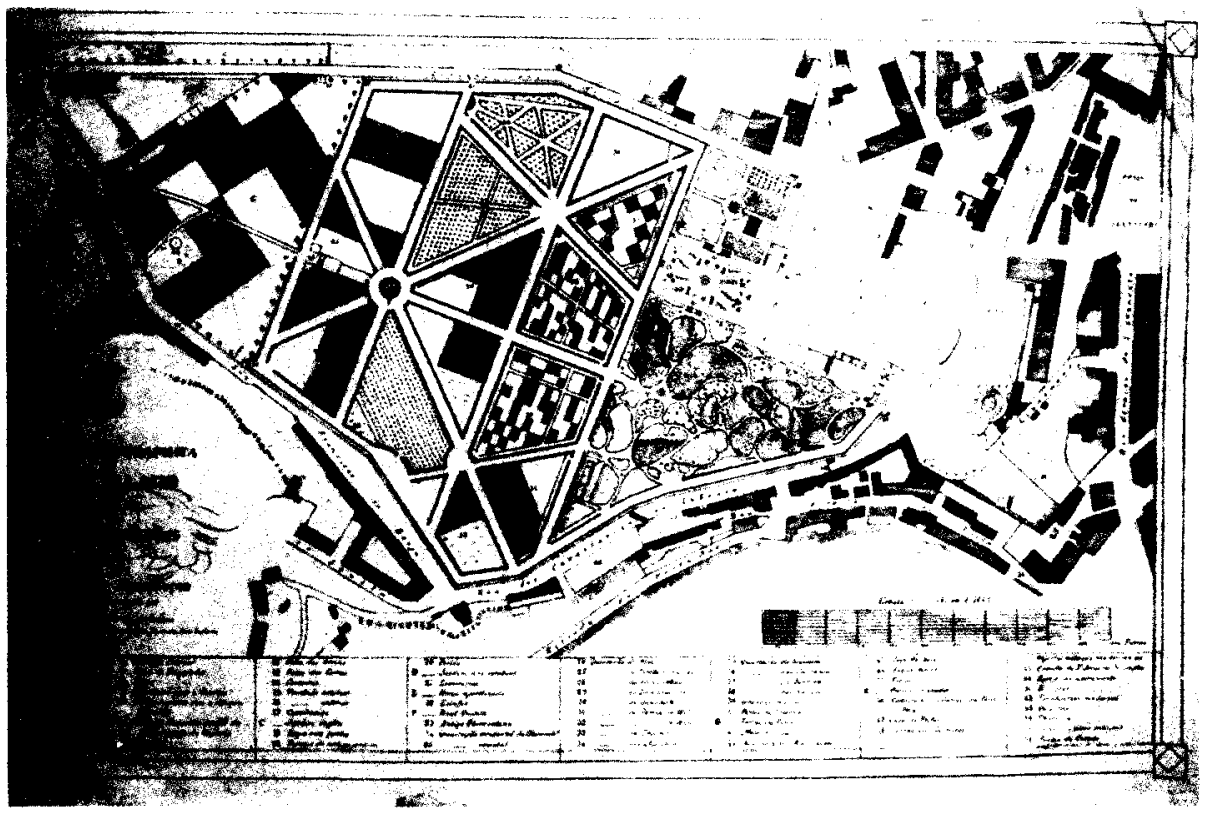

Fig.7 - Planta da Tapada das Necessidades em 1844. In: ANTT.

A experiência de Bonnard nas Necessidades, a par da sua sólida formação teórica, levou-o a escrever um pequeno livro no qual relatava as suas intervenções neste jardim: Horticulture et Arboriculture vegetaux introduits dans les cultures du Jardin Royal des Necessidades depuis sa restauration, escrito em 184115 .

A tapada vai sofrer inúmeras alterações sob a batuta de D.Fernando, as quais the vão modificar a estrutura conceptual barroca que se mantinha desde $D$.João $V$. A restruturação vai ser totalmente assumida, rompendo com toda a estrutura prévia. O que está em jogo é a forma de encarar a paisagem: até aqui, a tapada com seu traçado barroco impunha-se ao terreno, numa rede de longos caminhos traçados a régua e esquadro. $A$ filosofia de vida de D.Fernando encontrava-se no quadrante oposto, a veneração da natureza na sua forma selvagem transportava-se para uma visão dos jardins com formas curvas e suaves numa clara apologia à liberdade. O que se confronta neste terreno são duas visões contrárias da sociedade; absolutismo e liberalismo, que se vêem espelhadas em duas formas de pensar os jardins; o classicismo francês e o paisagismo inglês.

15 Telxeira, José, D. Fernando /I, Rei-Artista, Artista-Rei, Lisboa, Fundação Casa de Bragança, 1986 , pág. 166 


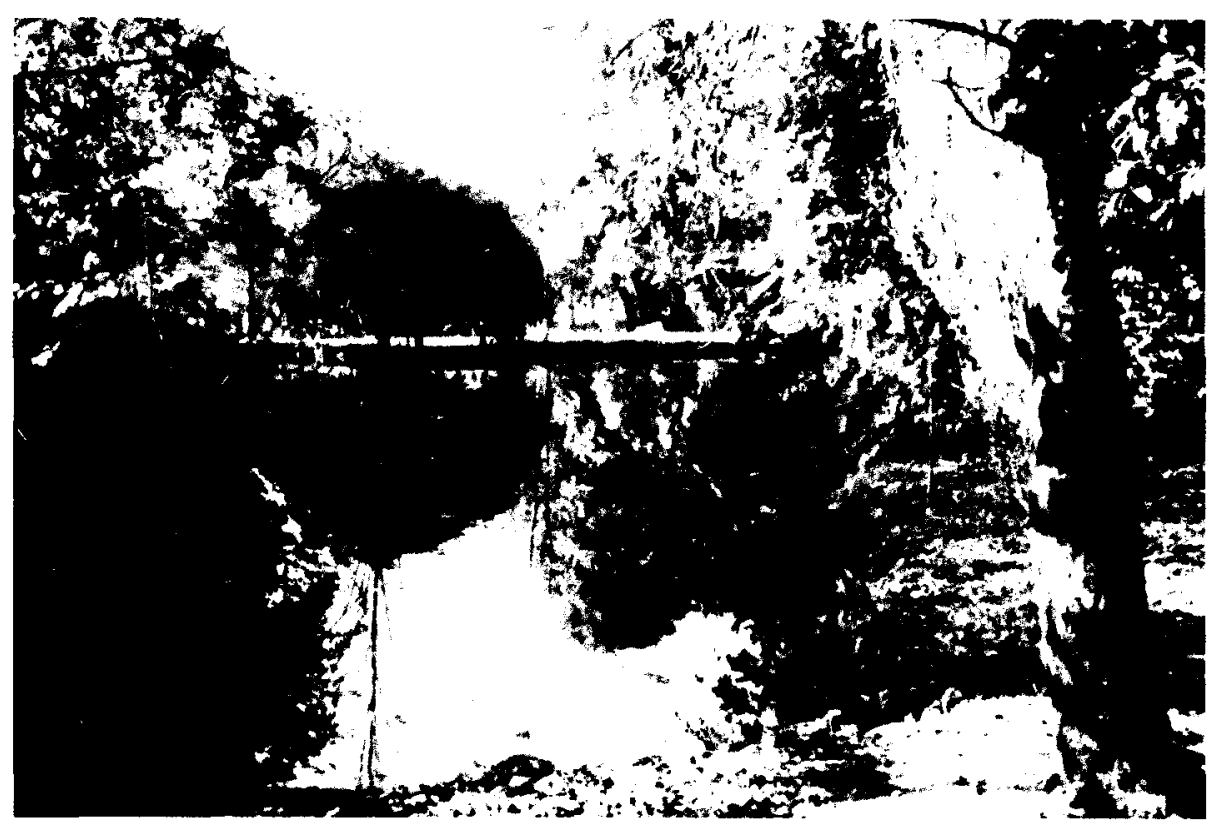

Fig.8 - Jardim Inglês . Foto: João Albuquerque Carreiras

O simbolismo deste espaço é de grande importância histórica. A sua construção deve-se ao monarca mais absoluto, D. João $\mathrm{V}$. Aqui se reuniram pela primeira vez as cortes após as guerras liberais, e para aqui veio viver D.Maria II. O significado desta ruptura no jardim encontra-se na demonstração clara de liberdade formal decorrente da nova liberdade social e política. Pela primeira vez em Portugal a família real cria um jardim liberto de restrições e espartilhos, rompendo sem transição com um estilo que vinha resistindo aos ventos de mudança.

A aplicação prática dos cânones paisagísticos ingleses não era contudo fácil. Os domínios envolventes dos edifícios não tinham a amplitude dos britânicos e os jardins portugueses tinham e continuam a ter uma grande clausura para o exterior, fechando-se sobre si mesmos. Esta terá sido a obra possivel, aquela que desbravou caminho para realizações mais ambiciosas, nascidas com menos constrangimentos e levadas a um maior grau de depuração. O seu exemplo máximo terá sido o Parque da Pena.

Neste processo o factor mais importante foi a renovação que a tapada sofreu ao nível da vegetação, com a introdução de inúmeras espécies exóticas. A relação de D.Fernando com a paisagem era ampla, descendo 
na escala até à planta como indivíduo. A beleza não estava apenas no todo, estava também em cada indivíduo que o formava. Cada planta tinha a sua personalidade e o seu lugar. Esta atitude reflectiu-se numa relação como que de coleccionismo de plantas, com uma incessante busca de novas espécies, procurando a sua aclimatação com vista ao seu emprego no jardim. Pode identificar-se este pensamento com o de um homem fulcral na evolução do jardim inglês, John Claudius Loudon16.

A execução deste projecto não foi feita como um todo. As obras das Necessidades foram faseadas, sendo executados pequenos projectos para cada zona. O motivo deste desfasamento terão sido contingências financeiras, já que Portugal não atravessava uma época desafogada e a hora não era de esbanjamentos. Exemplo concreto foi o recuo no primeiro projecto para a estufa circular.

Deve-se fazer aqui uma referência ao papel de D.Maria II e D. Pedro V nas obras das Necessidades. Este papel poderá parecer desvalorizado, mas de facto D.Fernando é a personagem que move este processo. Apesar de $D$. Pedro $V$ ter vivido nas Necessidades com sua mulher, D. Estefânia. de se conhecer o seu apreço pela tapada e de ter sido por sua ordem erguida a Estufa Circular, o fio condutor das obras realizadas nesta época é de facto o projecto idealizado por D.Fernando.

Num primeiro período (1836 - 1848) (Fig. 14b) é construído o jardim inglês, mantendo-se à partida a restante estrutura da tapada. É de crer que a introdução de novas espécies vegetais não extravasasse os limites deste jardim, uma vez que os canteiros são nomeados um a um, e dos seus nomes se retiram usos fundamentalmente agrícolas de pomar, vinha e terra de semeadura. O projecto original da estufa data desta fase, mas a sua concretização, baseada no segundo projecto, decorre já no reinado de $\mathrm{D}$. Pedro.

Estávamos em Agosto de 1841 quando, por ordem de D.Fernando, foi executada a primeira e maior obra desta época, um jardim ao estilo paisagista, implantado no seguimento, para poente, do Jardim de Buxo. Este espaço foi o embrião para a revolução operada na tapada. As alterações foram feitas pela mão do jardineiro Bonnard, sendo introduzidas variadas espécies exóticas.

A concepção deste espaço seguia a corrente estética do paisagismo inglês, sendo talvez o seu primeiro exemplo no nosso país, tornando-se como que num balão de ensaio para a grande obra romântica de D.Fer- 


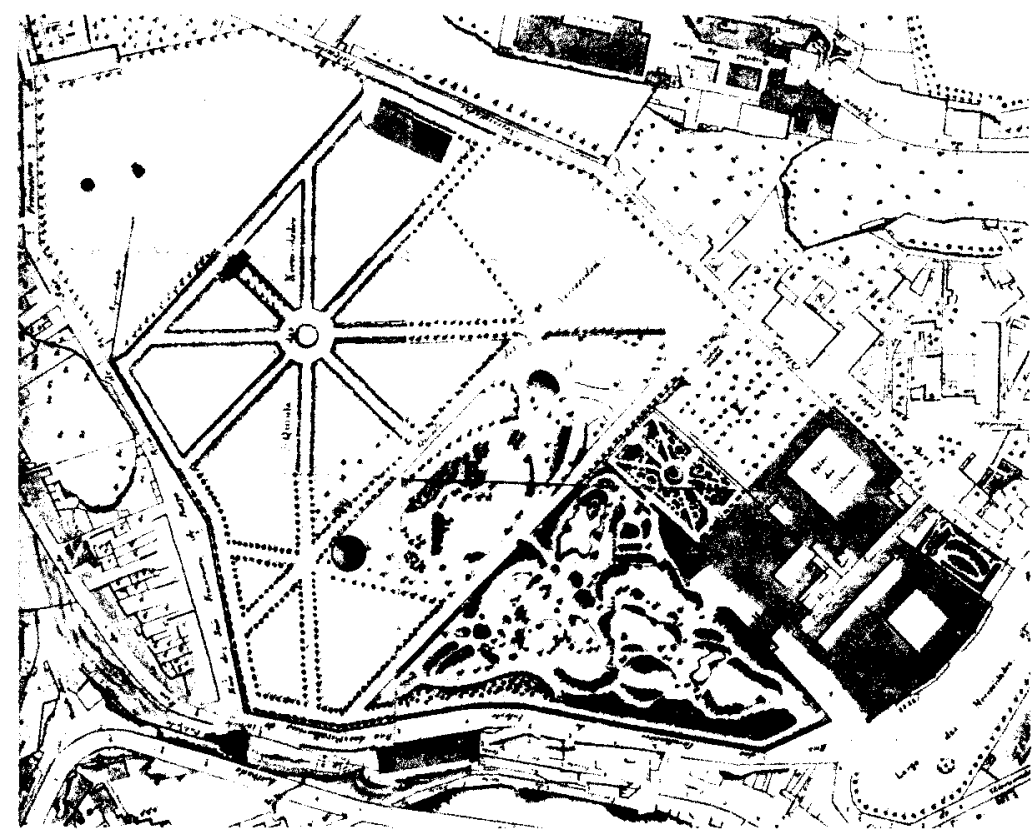

Fig.9 - Planta da Tapada das Necessidades em 1856

In: Câmara Municipal de Lisboa , Estudos Olisiponenses (CMLEO)

nando II, o Parque da Pena. Sobre este jardim disse Possidónio da Silva que era um «elegante e vistoso jardim inglês...nele existem os arbustos e flores as mais raras que concorrem a embelezar pelas suas diferentes qualidades, variadas cores e subtil fragrância; como a ornar com sumo gosto este recreio real deleitando a vista e embriagando o olfacto de todas as pessoas que conseguem o especial favor de admirarem o primeiro jardim que neste género tiveram os reis de Portugal» 17 .

O aspecto geral da tapada é nesta época assaz curioso (Fig. 7). O novo jardim aparece ainda totalmente espartilhado entre linhas estruturantes muito fortes, a nascente o jardim de buxo, a norte o restante terreno da antiga cerca oratoriana, ainda dominada pelas grandes alamedas que conduzem ao lago central.

O jardim oferece-nos dois novos lagos artificiais de forma irregular, envolvidos por vegetação do tipo ripícola, e uma profusão de "canteiros" também irregulares, de formas arredondadas, povoados por inúmeras es-

17 Descrição das Necessidades por Possidónio da Silva, A.H.M.F., Arquivo da Extinta Casa, Livro M 13, Maço 10, Doc. 19 


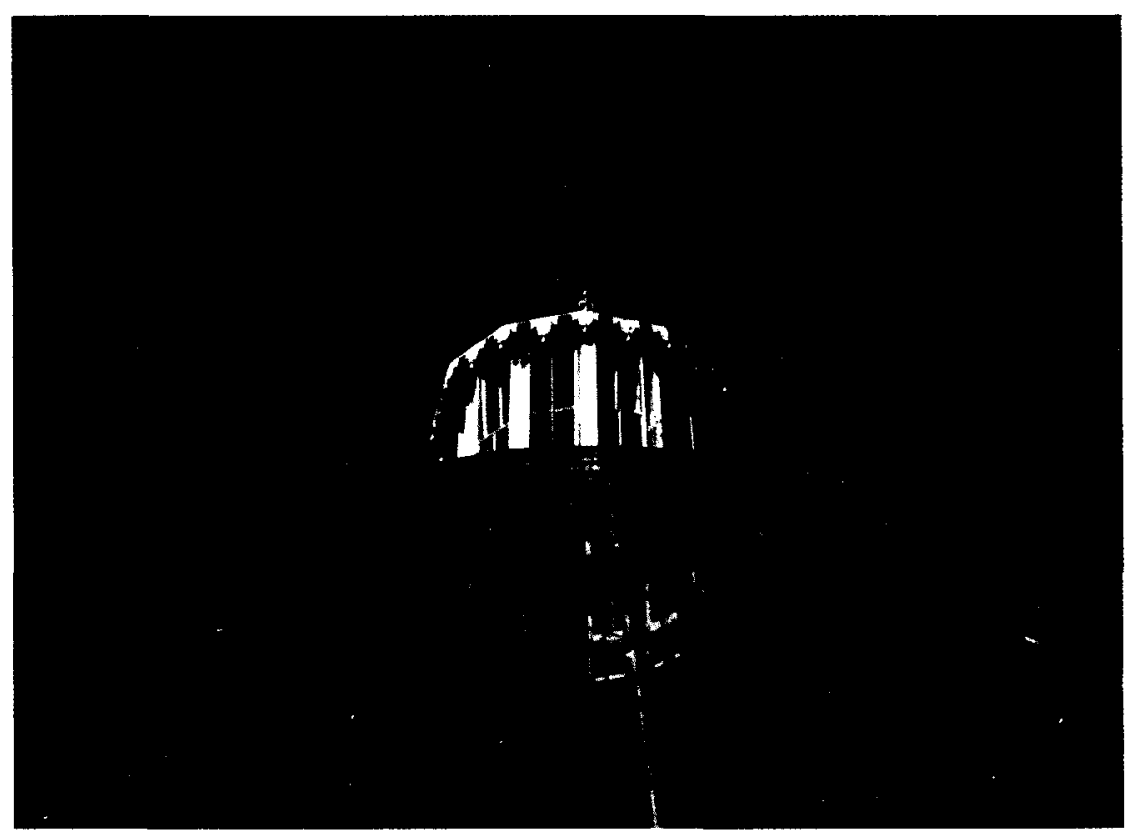

Fig.10 - Cúpula da Estufa

Foto: João Albuquerque Carreiras

pécies exóticas (Fig. 8). Estes elementos remetem para uma naturalização do espaço, que nos aparece contudo rodeado de muros e sem a amplitude desejável.

Numa segunda época (1848-1856) (Fig. 14c) verifica-se a construção de diversos edifícios, nomeadamente o Picadeiro, a Estufa e o Jardim Zoológico. O jardim inglês alarga-se, parecendo incluir a construção do relvado; no entanto, acima desta zona prevalece a estrutura barroca (Fig. 9).

Um largo relvado está situado abaixo da Estufa e da Casa Fresca, estando o seu topo coroado por uma mancha vegetal estratificada. Está contornado na sua totalidade por percursos pedonais, que ligam diversos elementos edificados. Este relvado tem um enorme impacto visual, uma vez que é das poucas clareiras existentes na tapada, criando uma zona de excelente exposição solar, o que o torna um dos melhores locais de estadia.

O picadeiro era um dos centros de diversão dos infantes, filhos de $D$. Fernando, como o ilustra o trecho de uma carta dirigida por um deles ao Visconde de Carreira, "Eu gosto muito de andar a cavallo e quando os 
manos voltarem, espero já saber. Às vezes monto sem estribos. As manas e o mano Fernando também andam a cavallo."18 A sua arquitectura era de grande beleza, ornada com azulejos e ferro trabalhado. Este picadeiro era considerado dos mais belos da Europa, restando hoje apenas uma vaga memória do mesmo após a sua destruição.

O primeiro projecto para uma estufa data de Setembro de 1844, sendo da autoria do Eng. Pézérat: Projet de serre ou jardin d'hiver pour la Quinta das Necessidades. Este projecto foi abandonado por ambicioso, dispendioso, e por a conjuntura política da época não ser favorável a projectos desta indole. A estufa para as Necessidades foi, no entanto, concretizado pela mão de D.Pedro $\mathrm{V}$, recorrendo-se então a um projecto mais simples, que hoje podemos admirar, e que foi

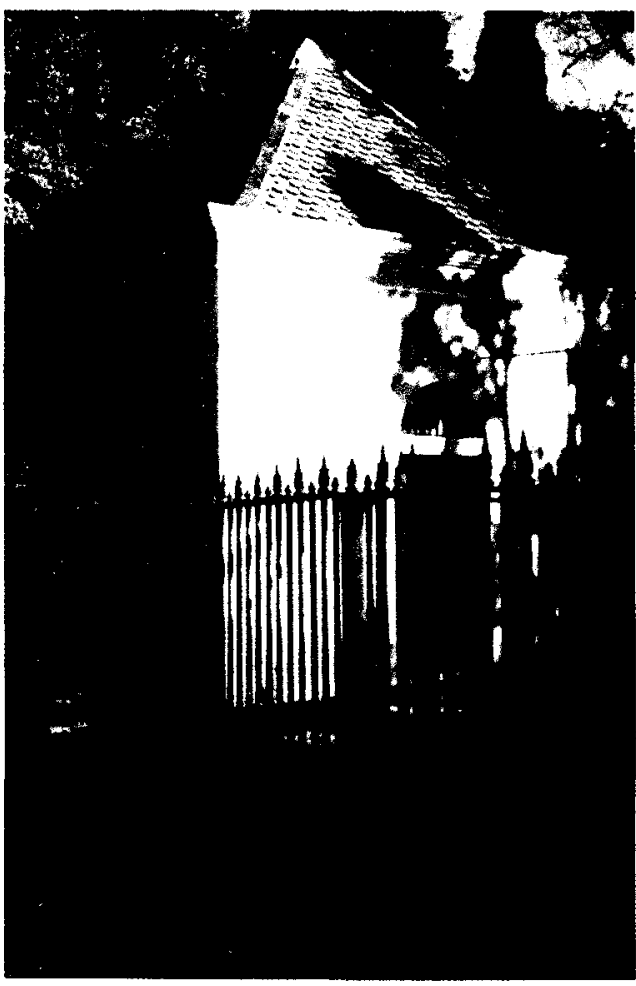

Fig. 11 Torreão do Jardim Zoológico Foto: João Albuquerque Carreiras executado em 1856-57 (Fig. 10).

O Jardim Zoológico é dos elementos que mais interesse desperta nesta tapada. A existência de uma zona reservada a animais - especialmente a aves - no tempo de D.Fernando, é um facto, conferido nas diversas notas de encomenda e notícias referentes à chegada de aves e outros animais, tais como: "Diversos fornecimentos de pássaros foram encontrados, bem como as gaiolas de arame amarelo, em malha miúda, outra ditas de 'viuva', ou de canas, bebedoiros, etc., fabricados por João Alberto de Morais» 19.

18 Correspondência com o Visconde da Carreira, A.C.B.(Arquivo da Casa de Bragança), Reservados, doc. n.? 34, 28-7-1851

13 ACB, Casa Real - Séc. XIX, Palácio das Necessidades, facturas de 23-8-1848 e de 18-2-1851 


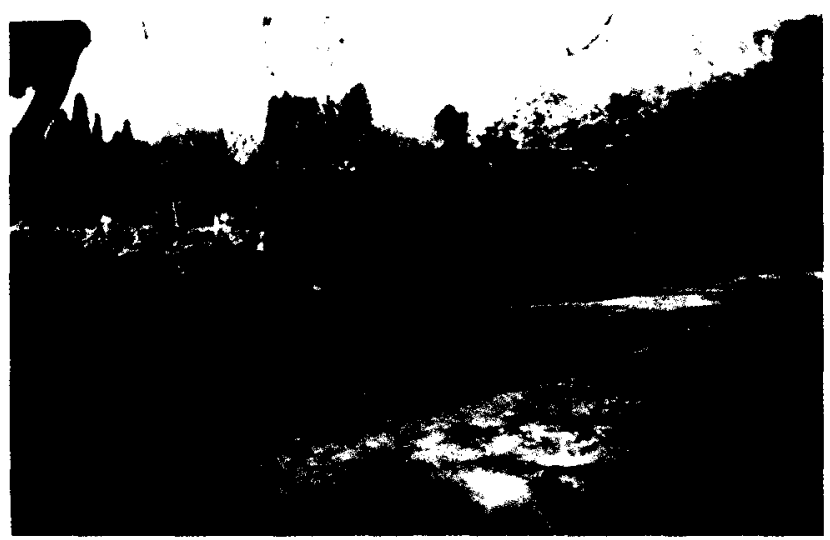

Fig. 12

Casa de Fresco

Foto:

João Albuquerque

Carreiras

Em Maio de 1839 chega do Brasil uma remessa de macacos e aves raras, que tem por destino as Necessidades20; no fim de 1850 foi enviada de Paris para Lisboa uma boa variedade de aves, reservada por certo para o mesmo jardim, entre elas um «canard à tête de quise de Terre Neuve», um "gypaête barbu male des Pyrenées», o mais belo de espécie que recebeu a medalha de ouro da exposição (anual de Aves na capital francesa) e um "sécretaire jeune du Cap»21; nascimento de pintainhos brancos em 185622, e a existência de rolas em 185423. Estes acontecimentos comprovam a existência nas Necessidades de uma zona de «jardim zoológico" ou aviário, supostamente localizada na zona agora chamada de campo de ténis. A existência de gradeamentos, que apontam para uma utilização de vedação, e de estruturas semelhantes a pequenos aviários, podem concorrer para comprovar esta teoria (Fig. 11).

Na terceira fase (1856-1896) (Fig. 14d) a irregularidade espraia-se por toda a tapada, desaparecendo qualquer vestígio da estrutura barroca, com a excepção do eixo do observatório - lago.

Unida por um muro de suporte à Estufa Circular, ergue-se a Casa Fresca ou Casa de Fresco, construída nesta época. A sua estrutura reveste-se de alguma estranheza, pois a água que a refresca situa-se na sua parte superior. Aqui existe um tanque, servindo a seu tempo para dar àquela casa um ambiente fresco, para além do efeito estético. O tanque é

20 Correspondência de D.Fernando com Sá da Bandeira, A.C.B., Reservados, doc.14, Carta de 17-51839

21 Factura de 30-XII-1850, do fornecedor Adolpho Mathias, agente de compras da Casa Real, A.C.B., Casa Real - Séc XIX, Paço das Necessidades

22 Carta de 8-5-1856, A.H.M.F., Cartório da Casa Real, Maço 10, doc. 181-1

23 ibidem, doc. 190-1, 1854 


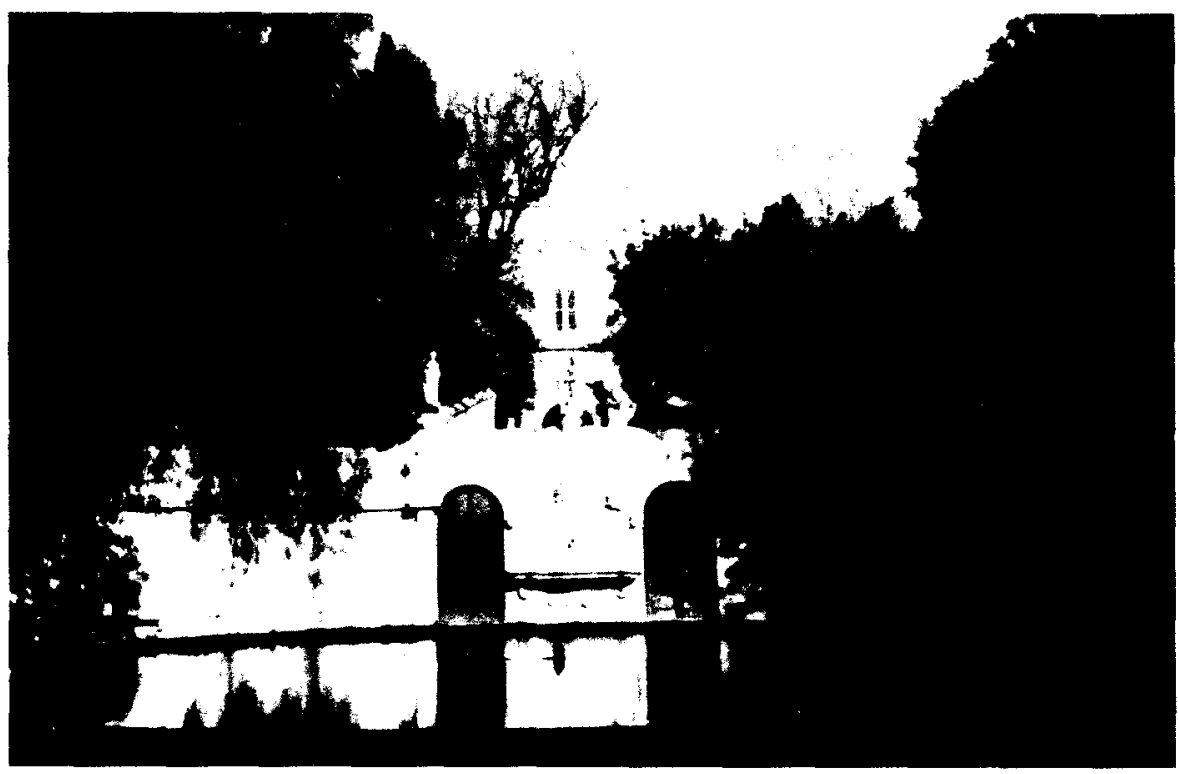

Fig.13 - Casa do Regalo e Lago Circular Foto: João Albuquerque Carreiras

rectangular, sendo circundado por um conjunto de vasos ornamentados. Num dos seus topos existe uma bica que lança água (Fig. 12).

A função deste edifício não é clara, no entanto podemos arriscar atribuir-lhe a função de conservação de sementes e plantas, num contraponto de aclimatação fria com a estufa quente.

A presença de D.Fernando trouxe para as Necessidades uma enorme variedade de plantas exóticas; deste facto é dado conta num artigo do Jornal de Horticultura Prática, escrito em 1876 por Edmond Goeze.

Para o autor, a árvore mais emblemática seria uma Jubea spectabilis, também conhecida por Palmeira Coquita do Chili, que teria nas Necessidades o mais belo espécimen da Europa. D.Fernando teria-a adquirido em 1858 ao Sr. Van-Houtte, plantando-a de imediato neste jardim. Por tempos deste artigo teria 13 pés e 8 polegadas de circunferência na base, por cerca de 32 pés de altura.

Entre as árvores notáveis distinguia ainda: a Livinstona sinensis Mart. ou Lantania borbonica Lam., árvore de origem chinesa pouco utilizada em Portugal, introduzida pouco tempo antes, da qual existiam alguns pés que prometiam grande desenvolvimento; o Sabal adansonii que tendo um 
apreciável crescimento, já tinha dado frutos que permitiram extracção de sementes, estando presente em vários vasos; Livistona australis ou Corypha australis, e a Seaforthia elegants ambas originárias da Austrália e um exemplar entre o conjunto de Cocus australis com 40 a 50 pés de altura e 2 de circunferência.

\section{Carlos - República - Declínio}

Após a morte trágica de $\mathrm{D}$. Pedro $\mathrm{V}$, sucede-lhe no trono $\mathrm{D}$. Luiz, que tencionava viver nas Necessidades. No entanto, verifica-se um enorme clamor do povo para que transfira a residência oficial para outro local. Esta atitude deve-se ao facto de terem morrido nas Necessidades vários membros da família real, daí o povo ter adquirido a superstição de o palácio estar amaldiçoado. D. Luiz era um rei muito querido pela população, que não queria para ele o mesmo destino de seu irmão e sua cunhada, que morreram nas Necessidades ainda jovens. O seu pai, D.Fernando, continuou no entanto a viver nas Necessidades com seu filho D. Augusto, vindo a morrer no palácio.

D. Luiz casa com D.Maria Pia de Sabóia, tendo um filho, D.Carlos, que Ihe sucederá no trono. Após o seu casamento com a rainha $D$. Amélia, D.Carlos opta por ir viver para as Necessidades, deixando o palácio da Ajuda para residência da Rainha - Mãe. A sua presença vai trazer nova vida ao palácio das Necessidades, com consequentes modificações na tapada.

Recorrendo a uma descrição de Câncio,24 podemos descrever a Tapada das Necessidades na época de D.Carlos como um jardim romântico, decorrente da obra feita por D.Fernando, que apesar dos anos passados manteria o seu esplendor. Os lagos, a vegetação exótica e luxuriante, as estátuas, a estufa. Confirmam-se também aqui as duas grandes intervenções de D.Carlos, a Casa do Regalo e o Campo de Ténis.

A Casa do Regalo, ou Atelier da Rainha D. Amélia, está construída no local onde outrora se encontrava o Observatório dos padres oratorianos. Data de 1889 a construção desta estrutura pela mão de D.Carlos, que aí quis implantar um local aprazivel para a sua mulher, a Rainha D. Amélia, poder utilizar como atelier de desenho e pintura.

24 "Illustração Portugueza" n. ${ }^{\circ} 48,49,50$, cit. por CÂnCIO, Francisco, Figuras e casos do passado, Lisboa, 1943, págs. $156-158$ 

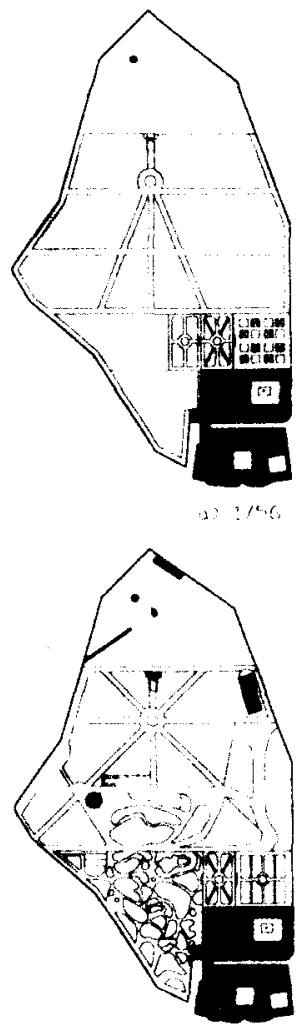

$\therefore \quad y 4$

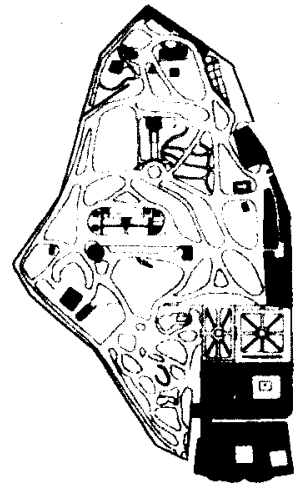

$\Leftrightarrow$ A t 00

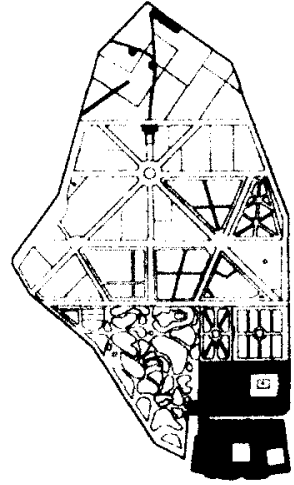

b) $: 844$

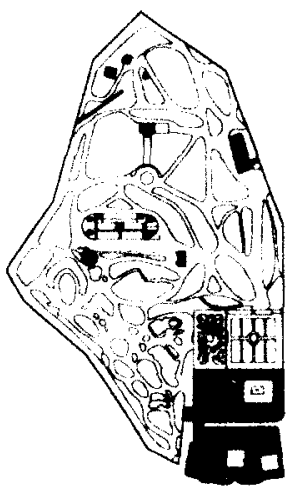

a. !sto

Fig. 14 - Planos de Época. a) 1756; b) 1844; c) 1856; d ) 1898; e) Actual Desenho: João Albuquerque Carreiras 
Este edifício localiza-se num ponto central da tapada, sendo que devido à topografia apresenta uma posição de domínio, destacando-se como um edifício de referência neste espaço. Encontra-se a oeste da Cateira, estando a fachada Sul ligada ao lago circular através de um eixo bem marcado. Este eixo estava coberto por uma treliça, o que deu origem a outro dos nomes pelos quais esta estrutura era conhecida, a Casa da Treliça (Fig. 13).

Pela mão de D. Carlos é construído um campo de ténis, num local junto do «jardim zoológico» de D.Fernando. Aí D. Carlos, conhecido sportsman, jogava ténis com os seus filhos, os príncipes D. Manuel e Luís Filipe.

Quando em 1908 se dá o regicídio, com a morte de D. Carlos e do príncipe Luís Filipe, D. Manuel II e sua mãe continuam a viver nas Necessidades, e é deste palácio que têm de fugir aquando da revolução republicana de 1910, durante a qual o palácio é bombardeado desde o rio, após o que $D$. Manuel de refugia nos jardins, de onde virá a fugir para Inglaterra.

Com este episódio final da história da monarquia em Portugal, a Tapada entra num progressivo processo de degradação que continua até hoje (Fig.14e).

\section{BIBLIOGRAFÍA}

andersen, Hans Christian, Uma Visita em Portugal em 1866, Lisboa, Instituto de Cultura e Língua Portuguesa, 1984.

Azevedo, Carlos, Solares Portugueses, Lisboa, Livros Horizonte, 1988.

Barbosa, INÁCIO DE VILHENA, “Real Quinta das Necessidades», Arquivo Pitoresco, n.? 18, Lisboa 1862, pág. 142.

Bowe, PatRick, Jardins de Portugal, Lisboa, Quetzal, 1989.

Cáncio, Francisco, Figuras e casos do passado, Lisboa, 1943.

Carita, Hélder, Cardoso, Homem, Tratado da Grandeza dos Jardins em Portugal, Lisboa, Circulo dos Leitores, 1990.

Carreiras, joão Albuquerque, Acerca das Necessidades, Trabalho de fim de curso em Arquitectura Paisagista, Instituto Superior de Agronomia, Lisboa, 1999, n.ed.

Carvalho, José MARIA de, Catálogo Oficial da V Exposição Nacional de Floricultura, Lisboa, C.M.L., 1944.

Concelçāo, Frei Cládio da, Gabinete Histórico, Tomo XI, Lisboa, Typographia Real, 1818.

Côrte-Real, Manuel henrique, Palácio das Necessidades, Lisboa, Ministério dos Negócios Estrangeiros, 1983.

Ferráo, Leonor, A Real Obra de Nossa Senhora das Necessidades, Lisboa, Ed. Quetzal, 1994. Mendes, Fernando, D. João $V$, Rei Absoluto, Lisboa, Livraria Editora, s.d. 
Ribeiro, Jose Silvestre, Historia dos estabilicimentos scientificos litterarios e artisticos de Portugal nos successsivos reinados da monarchia, Lisboa, Academia Real das Sciências, 1871 1914, Tomo III - 1873.

TelxeIra, José, D. Fernando II, Rei-Artista, Artista-Rei, Lisboa, Fundação Casa de Bragança, 1986.

VITERBo, F. SOUSA, Dicionário Histórico e Documental dos Arquitectos e construtores portugueses ou ao senviço de Portugal, Imprensa Nacional Casa da Moeda, Tomo III, Lisboa, 1922.

VIterbo, Francisco DE SOUSA, A jardinagem em Portugal, Coimbra, Imprensa da Universidade, 1909. 
